\title{
The Effect of The Mnemonic Keyword Method of Foreign Language Vocabulary Learning: Cognition and Metacognition Perspective
}

\author{
Muhamad Faqih Irsyad ${ }^{1}$ \\ Flinders University \\ e-mail: irsy0001@flinders.edu.au
}

\begin{abstract}
The Keyword Method (KWM) is a mnemonic method designed to assist learners in learning foreign vocabulary. The method encompasses two processes, namely, the similarity of the words in sound(s) or the similarity of the keyword spoken with foreign language words and created mental images. This case study of the intervention involved a 26 years old student who had newly commenced as a first-year Indonesian studies student at Flinders University, Adelaide. She is a locally born Australian student who speaks English as her native language. To interpret the result findings, the checklist method (consisting of correct, doubt, and no responses), descriptive analysis, and interviews, as well as observations, have been applied in the KWM implementation. The results proved that the KWM has successfully assisted the learner in improving her Bahasa Indonesia, both in acquisition and retention, in a more effective manner compared to her other study strategies. This was especially apparent after conducting the immediate and delayed comprehensive test. The subject was also able to generate self-regulated learning. This indicated that the subject is able to metacognitively, motivationally and behaviorally utilize her cognitive sources to control the tasks. Cognitive and metacognitive processes of the KWM implementation, involving the detailed information processing of the learner, are discussed here.
\end{abstract}

KEYWORDS The Keyword Method, Cognition, Metacognition, Self-regulated learning

CITATION Irsyad, M. F. (2019). The effect of the mnemonic keyword method of foreign language vocabulary learning: cognition and metacognition perspective. Cognicia, 7, (3), 390-410.

Acquiring vocabulary knowledge is very pivotal for mastering language, especially Foreign Language (FL) learning. Krashen (1989) states that the main problem in mastering language is the lack of vocabulary. Learners feel difficulty understanding a new language when they do not have enough vocabulary, especially in understanding content knowledge (See Harmon, Wood, \& Medina, 2009; Kelley, Lesaux, Kieffer, \& Faller, 2010). Vocabulary knowledge has a significant impact on different learning situations such as in reading (Greaney, 1970; Hemphill \& Tivnan, 2008), writing (Olinghouse \& Wilson, 2013; Staehr, 2008), Speaking (De Jong, Steinel, Florijn, Schoonen, \& Hulstijn, 2013; Koizumi \& In'nami, 2013) and listening (Stæhr, 2009; Staehr, 2008; Wells, 1985). Therefore, vocabulary knowledge is necessary for students, and it definitely determines whether learners become academically successful (Kelley et al., 2010), especially in FL learning.

Consequently, most researchers seek to devise the most effective way to assist students enhancing their FL vocabulary learning. The keyword method has become one of the most 
preferred techniques, that has been extensively researched in various countries, for FL vocabulary teaching method in order to improve students' FL vocabulary learning.

\section{The Keyword Method (KWM)}

The KWM has become an effective teaching method for learning Foreign Language (FL) vocabulary. The method initially was developed by Atkinson (1975) and his associates (Atkinson \& Raugh, 1974, 1975; Raugh, Schupbach, \& Atkinson, 1977). They demonstrated the technique in order to facilitate learners acquiring Spanish and Russian vocabularies. Furthermore, Atkinson and Raugh (1975) defined this strategy as consisting of three stages. The first stage requires the subject to associate the spoken native foreign word with the keyword that has similarity in sound(s). This confirms what Paivio (1990) stated that the development of vocabulary in a second language is significantly related to the acoustical similarities between the first language and the target word. Nevertheless, other experts argue that this is not only formed by sound but also any similarity between the foreign word and the native language (See Dolean, 2014; Raugh et al., 1977). Thus, learners can associate the new word and the keyword quickly due to the similarity of an acoustic link between the words.

The second stage requires the learners to form a mental image of the keyword in order to create a meaningful interaction in which the keyword is linked to the English translation by generating an imagery link. Imagery link in this strategy is very helpful to generate the vividness of association in terms of a pair of unrelated English words as a mnemonic aid (Atkinson, 1975). Through the process of association, learners can memorize a new vocabulary easier and in a more efficient manner. The last stage is avoiding vocabulary that leads to ambiguities as may happen when a keyword is associated with several foreign words.

Consider a few examples from Indonesian and English vocabulary below. In Indonesian, the word "beras" (pronounced bara:f) means "rice" in English. It contains a sound that resembles the English word "brush". Employing the Indonesian word "beras" as the new word with the keyword "brush", learners can potentially form mental imagery of the keyword "interacting" with English translation like using "brush" to wash "beras" or two brushes on the "beras" (See Figure 1). Another example is the Indonesian word "kaca" (pronounced something like "kæca") that has similarity with "cat". Using the new word "kaca" as the Indonesian word with "cat" as the keyword can generate the relevant mental imagery for learners; they might imagine "a cat looks herself in the glass"

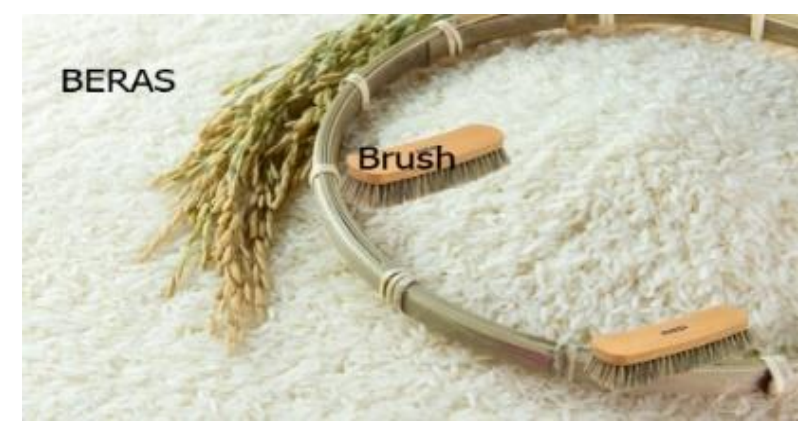

BERAS - brush - RICE

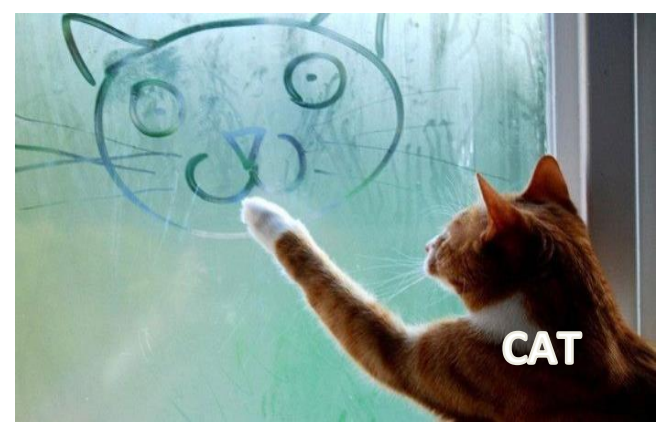

KACA - cat - GLASS 
Figure 1. two illustrations of how mental images might be employed to associate a spoken Indonesian word with its English translation. (The pictures taken from (Industries, 2017; Miminku, 2016; Pediwear, 2019)).

Many researchers around the world have proven the effectiveness of the KWM in a variety of learning situations. For example, the method has been carried out for students (Atkinson, 1975; Atkinson \& Raugh, 1974, 1975; Shapiro \& Waters, 2005; Siriganjanavong, 2013), young children (Avila \& Sadoski, 1996; Pressley, 1977; Wyra, Lawson, \& Hungi, 2007), teenagers (Baleghizadeh \& Ashoori, 2010; Rodriguez \& Sadowki, 2000) and the elderly learners (Gruneberg \& Pascoe, 1996). Furthermore, this technique has been used also for teaching disabled children (Condus, Marshall, \& Miller, 1986; Mastropieri, Scruggs, \& Mushinski Fulk, 1990; Pearlman, 1990).

The debatable issues concerning this strategy come from other researchers' differing standpoints. The paramount issue that often emerges is whether the learners ought to generate the keywords on their own or have them provided by researchers. Some research findings suggest that the keywords generated by the researchers yield better vocabulary recall (Atkinson, 1975; Atkinson \& Raugh, 1975; Troutt-Ervin, 1990). While other researchers also argue that learners generating their own keywords yield better vocabulary recall (Pressley, Levin, \& Delaney, 1982; Roberts \& Kelly, 1985). Interestingly, some other researcher did not find any significant difference related to whom will generate the keywords (Mastropieri, Scruggs, Levin, Gaffney, \& McLoone, 1985; McLoone, Scruggs, Mastropieri, \& Zucker, 1986). Furthermore, some researchers have attached interesting pictures in the KWM process and judged that pictures could assist the learners in generating imagery link (Pressley, 1977; Pressley \& Levin, 1978), while others argue that learners would perform better if they were able to generate the imagery link by themselves (Atkinson, 1975; Atkinson \& Raugh, 1975; Troutt-Ervin, 1990). A different viewpoint also comes from Campos, González, and Amor (2003) preferred to ask the learners to make a drawing as stated by Paivio (1969) that drawings can be helpful in generating direct recall especially the word pair.

Furthermore, preselection words as recommended by Atkinson \& Raugh $(1974,1975)$ also continue to be debated. They argue that image-able words are the most preferable words that potentially can be used in this method. Nouns illustrate the image-able word so that learners can produce strong images adhering in the memory. Dual coding theory introduced by Paivio (1971) has differentiated between the verbal code and non-verbal code. Non-verbal codes have significantly illustrated high imagers than abstract words. Up to now, some researchers have elaborated and developed the KWM implementation instead of following the explanation (Atkinson \& Raugh, 1974, 1975). Interestingly, some researchers attempted to combine either noun, abstract, adjective or verb vocabulary in their experiments (Mastropieri et al., 1990; Pressley, Levin, \& Miller, 1981; Van Hell \& Mahn, 1997). An illustration of this case is the study investigated by Pressley et al. (1981) that found 76 fifth graders enrolled in two elementary schools were researched using concrete and abstract items. The result showed that there was no significant difference amongst the keyword variations. These findings are contrary to Atkinson \& Raugh $(1974,1975)$ that have limited the word variation in the KWM implementation.

Cognitive and Metacognitive underlying the KWM strategy 
Consider the first step when the learners commence to study the KWM. The learners will allocate their attention so it will be processed as a sensory input and sensory register. Attention, in the initial process of processing information, is the crucial instrument to establish the process of concentration on specific features or certain thoughts or activities (Anderson, 2005; Bruning, Schraw, \& Ronning, 1999, 2010; Goldstein, 2014). In particular, attention is most often triggered by a sensory experience (Medium, 2018). When the stimulus is identified, e.g. the KWM process that involves acoustic link and imagery link, this gets encoded into ShortTerm (or working) Memory (STM). Goldstein (2014) illustrated STM as a process occurring when learners give attention to present and then think about it or remember it that they have just read. The initial step of activity can generate students' awareness regarding studying the KWM to enhance their learning skills. Attention also allows learners to allocate all the limited cognitive resources in sensory memory to the task at hand. This ultimately leads to the better perception of stimuli and sensory registration of information (Bruning et al., 2010). Therefore, students can determine the decision making of perception as the extraction of meaning. However, attention and sensory memory are limited resources to maintain stimuli (Anderson, 2005; Bruning et al., 2010).

According to Craik and Lockhart (1972), in encouraging better cognitive analyses, students ought to get involved in the "deep part" of processing learning activities. In other words, this deep processing in the KWM is more oriented to meaning that eventually influences the recall performance. Shapiro and Waters (2005) said "the process of creating a keyword and an interaction requires a certain amount of engagement with the word and its meaning" (p. 135). The KWM in this context requires learners to get involved in the task of attaching meaning to be learned. Cognitive effort is also needed to build better recall performance, particularly when interpreting meaning (Walker, Jones, \& Mar, 1983). Even when the capacity to pay attention is extremely limited (Just \& Carpenter, 1992). Sweller (2011) proposed that learning secondary information, such as foreign languages, ought to consider the limited capacity of human cognitive architecture, this being the capacity of working memory and long-term memory. Preselection of the KWM is considered important to cope with the issue of cognitive load as asserted by Atkinson and Raugh (1974, 1975).

On behalf of this matter, dual coding theory developed by Paivio $(1969,1971)$ account for both the verbal code and the non-verbal code. These codes enable the overlapping of specifying the types of words memorised (Shapiro \& Waters, 2005), especially in the KWM implementation. Paivio (1971) explained the theory by differentiating between the verbal code and non-verbal code. The verbal code represents and processes language in all its forms, such as speaking, writing, etc. while non-verbal code deals with the mental representation. Sadoski (2005) stated "mental imagery is the primary cognitive form of nonverbal representation" ( $\mathrm{p}$. 222). According to Paivio (1969), words can be classified by at least in two kinds of associations. Firstly, concrete words can be associated with concrete objects and events as well as the association with other words e.g. leaves and banana. The concrete words are more likely to develop to a direct sensory referent (Ernest \& Paivio, 1971; Sadoski, 2005). Secondly, abstract words derive from an intraverbal experience that is difficult to imagine as an associated visual code, e.g. true and real (See Paivio, 1969, 1971; Sadoski, 2005; Shapiro \& Waters, 2005). In reference to the second and third stages of the KWM implementation cited above, Atkinson \& Raugh, $(1974,1975)$ argued that a good keyword is an image-able word. This accords with what Ernest and Paivio (1971) found which is concrete words showed high imagers than 
abstract words. The KWM process runs successfully due to the power of imagery link in it (Raugh et al., 1977; Shapiro \& Waters, 2005).

Another theory that relates to this strategy is schema theory. This theory is very beneficial for recognizing new information. Schemata can be defined as data structure that may represent generic concepts stored in memory (Bruning et al., 2010; Rumelhart, 2017). This data, furthermore, in regard to the KWM, are the subjects' sufficient prior knowledge that enables them to perform better in terms of allocation attention and improving STM function when encoding, as well as retrieving, information for Long-Term Memory (LTM). Besides, the familiarity of the words for the subjects in this technique considerably effects generating associative learning (Desrochers, 1982). The subjects are eventually able to associate a new word with a native spoken word. This is retained in LTM, a term that can be defined as an "archive" of information developed over period of time (Bruning et al., 2010). The process of retrieving the information from the past experiences is linked to memory well-known as episodic memory. Tulving (1972) described episodic memory as association with the past place and activity and semantic memory as association with general factual knowledge.

Shapiro and Waters (2005) explains the method of loci that can be an alternative to easily recall information through employing the KWM implementation in which subjects can utilize a familiar place and activity in order to remember a list of items. By contrast, learners experience difficulty in associating the words when they do not have any related information in their LTM. Also, it leads them to generate poor imagery link. As stated by Adams (1994), students' background knowledge will influence their performance in terms of generating information particularly in perception, pattern recognition, and forming meaning (Adams, 1994). Bruning et al. (2010) states "memory for new information is seen as a product of the learners' perceptual and cognitive analyses performed on incoming information" (p. 77). Learners in turn, link what they already know towards new information in order to produce their own structures for developing information. These kinds of activities will enhance memory retention in which the process initially derives from STM.

In terms of metacognition, Bruning et al. (2010) describe metacognition as the process of 'thinking about thinking' to enhance learning. According to Flavell (1979) metacognition has a pivotal role in learning that encompasses all dimensions of writing, listening, reading, memory, etc. He added metacognition may identify the self-cognition process when solving an issue. While Hasselhorn and Labuhn (2011) defined metacognitive as a number of activities, experience and phenomena linked to the knowledge and control of one's own cognitive functions such as perceptions, learning, memory, and understanding. Besides, metacognition cannot be separated by the term of awareness. With metacognition, learners can utilize the use of extensive knowledge in order to collaborate with certain strategies to accomplish learning goals (Bruning et al., 2010; Flavell, 1979).

Metacognition also refers to the kinds of activity that are involved and the self-knowledge received, through thinking and controlling, one's thinking (Proust, 2010). This is very related to strategy use (Bruning et al., 2010). When learners are capable of determining what kinds of strategy apply to the KWM (See Wyra \& Lawson, 2018), they potentially can better operate functional working memory (Dempster, 1985). An example is when learners deliberately are able to select one of the foreign words that are very similar to the native word pair. Then they have attempted to retrieve the proper word form LTM instead of getting confused what ought to be recalled. They also can utilize the method of loci as explained above to produce new and 
relevant information for the KWM implementation. As a result, learners can make their thinking more visible when they can use their metacognition. Through metacognition, they enable to control a host of other cognitive skills (Forrest-Pressley \& Waller, 2013). Therefore, this can assist the learners' recall performance in regards to the KWM and the effect on other students' performances in any learnings situation specifically in FL learning (Kelley et al., 2010).

\section{Self-regulated learning}

In term of retaining vocabulary better, self-regulated learning can be considered aspect that most needs investigating in more detail. Self-regulated learning involves learners to be cognitively and metacognitively aware in term of the use of vocabulary learning strategies in order to achieve better vocabulary acquisition and retention. Self-regulated learning is defined as the ability to monitor, assess, evaluate, and regulate one's own behavior (Schunk \& Ertmer, 2000; Schunk \& Zimmerman, 1994). Zimmerman (2000) defined self-regulated learning as "self-direct process" in which learners metacognitively, motivationally and behaviorally transform their mental abilities into academic skills. He explained that self-regulated learning involves three principals namely: metacognitive awareness, strategy use, and motivational control.

This theory also encourages learners to activate and sustain goal-directed actions and behaviors (Schunk \& Ertmer, 2000). This eventually influences the learners to control and manage their own thoughts, feelings and actions to achieve their learning goals (Bruning et al., 2010; Schunk \& Zimmerman, 1994; Zimmerman, 1990). According to (Bruning et al., 2010) in this theory, strategies are imperative so that the leaners can encode, represent, and retrieve information. Strategies can assist skilled learners to utilize their limited resources effectively and efficiently. In other words, when students use self-regulated learning, they employ cognitive and metacognitive strategy to control the tasks (Pintrich \& De Groot, 1990; Zimmerman, Bandura, \& Martinez-Pons, 1992).

Justification and Hypothesis

The KWM has been indicated as one of the best solutions, in terms of learning foreign vocabulary, to gain better acquisition and retention. Many researchers have proven the effectiveness of KWM in enhancing students' capacity for remembering foreign words in different languages around the world, such as Spanish (Atkinson, 1975; Pressley, 1977; Wyra et al., 2007), Thailand (Siriganjanavong, 2013), and Pakistan (Baleghizadeh \& Ashoori, 2010), Korean vocabulary (Griffith, 1981), French (Desrochers, 1982; Willerman \& Melvin, 1979), Chinese (Wang \& Thomas, 1992), and Dutch (Van Hell \& Mahn, 1997). From such extensive research, the KWM eventually has become the most effective way for English foreign learners to acquire new vocabulary.

Nevertheless, not many research discoveries have specifically discussed the correlation between the KWM strategy and cognitive and metacognitive processes. So far, the researcher found some relevant research findings. These are discussions of the cognitive processes underlying the KWM strategy Shapiro and Waters (2005), the vocabulary involvement towards working memory (or STM) and LTM Morra and Camba (2009) as well as the role of phonological loop in vocabulary learning Baddeley, Gathercole, and Papagno (1998). More specifically, no research findings have scrutinized the effect of the KWM in terms of generating 
self-regulated learning learner through further discussion. Consequently, here may be the first experiment in terms of Indonesian language beneficial for Indonesian studies learners. Therefore, this strategy hopefully supports Indonesian studies students in enhancing their foreign vocabulary acquisition and retention in order to successfully achieve a better academic performance.

Through these findings above, the hypothesis in this research will be outlined as follows: Firstly, the KWM will significantly support a first-year Indonesian studies student to improve her Bahasa vocabulary acquisition and retention in comparison with her current study method. Secondly, through the KWM, the subject will be able to generate self-regulated learning in her foreign vocabulary learning. Thirdly, the students' cognition and metacognition will actively engage in the KWM implementation.

\section{METHOD}

The subject is a first-year Indonesian studies student at Flinders University. She is originally an Australian student who speaks English as the native language. She is 26 years old. During her study, she is challenged in her Indonesian studies. Especially, she judges herself that she easily forgets Indonesian words although she tries to memorize them. As a result, she often experiences difficulty in her study and in turn, this detracts from her potential achievements. Also, this makes her less confident engaging in conversations with native speakers.

Generally, there were 23-word pairs that have been selected out of 33-word pairs. The words encompass Indonesian-English concrete noun that consists of two syllables and some, one syllable. To ensure the same comparable words of difficulty in conducting an intervention, the participant was asked to answer from each word either two syllables or one syllable in the prior commencing intervention both pre- and post-intervention. Those words were selected on a random and even basis. The subject was merely required to respond "yes" or "no" from each question asked. If the subject said "yes"; it means the word ought to be replaced with other remaining words; because the subject already knows the word. However, when the subject said "no"; it indicated that such word could be employed in the list of word pair items.

It is important to note that all word pairs provided were not tested when the final 10word pair has been identified in each prior intervention, both pre- and post-intervention. Therefore, there were final 23 words pair that were used, and the other remaining words were deleted. This intervention will be carried out three stages namely pre-intervention, intervention, and post-intervention. Both pre- and post-intervention employed each 10-word pair, while the intervention session employed 3-word pair. The intervention was done in a particular room and utilized a PowerPoint slide.

\section{Pre-intervention}

After finding out the final 10 new foreign words (Table 1), the PowerPoint of the 10 new foreign words and with its translations was displayed to the subject. The subject was required to do the best the subject could to memorize them. The subject was given 20 seconds per word (2 minutes in total). After 2 minutes, the subject was asked to comprehensively do the immediate test in order to examine her acquisition and retention. The subject also was tested a delayed comprehensive test after one week without warning/information early. 
Table 1

\begin{tabular}{cc}
\hline $\begin{array}{c}\text { New words } \\
\text { (Indonesia) }\end{array}$ & $\begin{array}{c}\text { English } \\
\text { Translation }\end{array}$ \\
\hline Balok & Beam \\
\hline Batu & Stone \\
\hline Kupon & Coupon \\
\hline Pel & Mop \\
\hline Akar & Root \\
\hline Tang & Pincers \\
\hline Rok & Skirt \\
\hline Gorden & Curtain \\
\hline Kaca & Glass \\
\hline Boneka & Doll \\
\hline
\end{tabular}

Intervention

In this stage, the subject was trained and taught through the presentation. According to Atkinson (1975) in applying the KWM, the KWM displayed a series of foreign words to the subject. When each foreign word is pronounced, its keyword and the English translation are exposed. The instruction was illustrated as follows: Firstly, a brief explanation of the KWM strategy including why the KWM works well and what the subject ought to do. Secondly, practice in three examples provided (Table 2). Such three words included one word in one syllable word and two words in two syllables. This is to represent all the words that would be used in this intervention. To illustrate, as you can see (while pointing the word on the slide and pronounce it), the Indonesian word "bir" ("alcohol" in English translation) as the new foreign word sounds like "beard" as the native spoken English. You can identify through the sound that is very similar, or also both words itself. These words of "bir" and "beard" is one syllable. Hence, the new foreign word "bir" really matches with the spoken language of "beard" as the keyword. Furthermore, at the same time, the subject was instructed to follow along during the presentation such as asked the subject to think and imagine the new foreign word with its translation together with the keyword as the spoken native English. An interactive image was orally provided to the subject. Also, the subject was asked to illustrate various imaginations orally speak to the researcher. The same instructions were explained with other remaining words.

Table 2

\begin{tabular}{ccc}
\hline $\begin{array}{c}\text { New words } \\
\text { (Indonesia) }\end{array}$ & $\begin{array}{c}\text { Keyword } \\
\text { (English) }\end{array}$ & $\begin{array}{c}\text { English } \\
\text { Translation }\end{array}$ \\
\hline Beras & Brush & Rice \\
\hline Bir & Beard & Alcohol \\
\hline Emas & Mouse & Gold \\
\hline
\end{tabular}

Post-intervention

In this stage, the subject was tested with other remaining words to seek out the final 10word pair that the subject did not know. These words were used to implement the KWM in this 
post-intervention stage (See Table 3). These words have comparable words with preintervention that consists of two syllables and one syllable word list selected randomly from the items. The subject was required to carry out the KWM strategy as the intervention following what the subject has been learned. The subject was given 2 minutes, the same as the previous intervention. After using the KWM, the subject was asked to comprehensively carry out the immediate test. The subject also was asked to carry out the delayed test one week later without information or warning early. The aim is to assess what the subject acquired from the memorization particularly her vocabulary acquisition and retention. Comparing between preand post-intervention was needed to analyse and find out whether or not the KWM works well to boost her English FL vocabulary.

Table 3

\begin{tabular}{ccc}
\hline $\begin{array}{c}\text { New words } \\
\text { (Indonesia) }\end{array}$ & $\begin{array}{c}\text { Keyword } \\
\text { (English) }\end{array}$ & Translation \\
\hline Mata & Mat & Eye \\
\hline Bor & Board & Drill \\
\hline Hati & Hat & Hearth \\
\hline Ban & Banana & Tire \\
\hline Candi & Candy & Temple \\
\hline Lem & Lamb & Glue \\
\hline Kapur & Cupboard & Chalk \\
\hline Babi & Baby & Pig \\
\hline Koper & Paper & Suitcase \\
\hline Helm & Hammer & Helmet \\
\hline
\end{tabular}

Ethic

In conducting educational intervention, the researcher has gained the ethics approval from the Flinders University Social and Behavioral Research Ethics Committee (SBREC). There are several forms of ethics that have been given at the beginning of intervention to the subject such as the letter of information from the college of education, psychology and social work, the latter of information from the researcher and consent form for interview and observation. The aim of these letters is to give detailed information at the beginning of the intervention in order to assist the subject to comprehensively understand the research aim of intervention. Besides, these letters are the procedure of the research that consists of statements, anonymity, confidentiality, implications for the participants and other related matters. The researcher also attaches a direct contact number or e-mail if there are any further enquiries about the project.

\section{RESULT}

The study examined the effectiveness of the KWM on vocabulary acquisition and retention of a first-year student who studies Bahasa at Flinders University. Also, this is to test whether the KWM is able to support the subject in order to establish her self-regulated learning. Cognition and metacognition in the KWM implementation are provided in the analysis. Based on result findings from the investigation, the KWM is very effective in supporting the subject to memorize FL language both vocabulary acquisition and retention compared to her strategy. 
Through the KWM, the subject is able to generate self-regulated learning in her learning process. Besides, cognition and metacognition process has a significant role in the KWM implementation.

Given this is the case study employing a participant, there are two main methods in measuring this intervention. Firstly, the checklist method measured whether or not the KWM can be judged to be a successful strategy in studying FL memorization. The checklist method consists of Correct, Doubt, and No response. Correct means the subject is able to mention all words properly either new word, the keyword or the translation; Doubt means the subject is uncertain to mention properly the pair-word, and No response means the subject cannot answer or mention any single word. Descriptive analysis was also employed to interpret the data. Secondly, the interview session was employed in elaborating the subject's experience and feeling toward the KWM strategy. To illustrate, the researcher outlines Figure 2 that depicts the probability of the correct, doubt and no response result as comparing pre-and post-intervention carried out on the immediate comprehensive test. While Figure 3 describes the result after conducting the delayed comprehensive test as comparison pre-and post-intervention

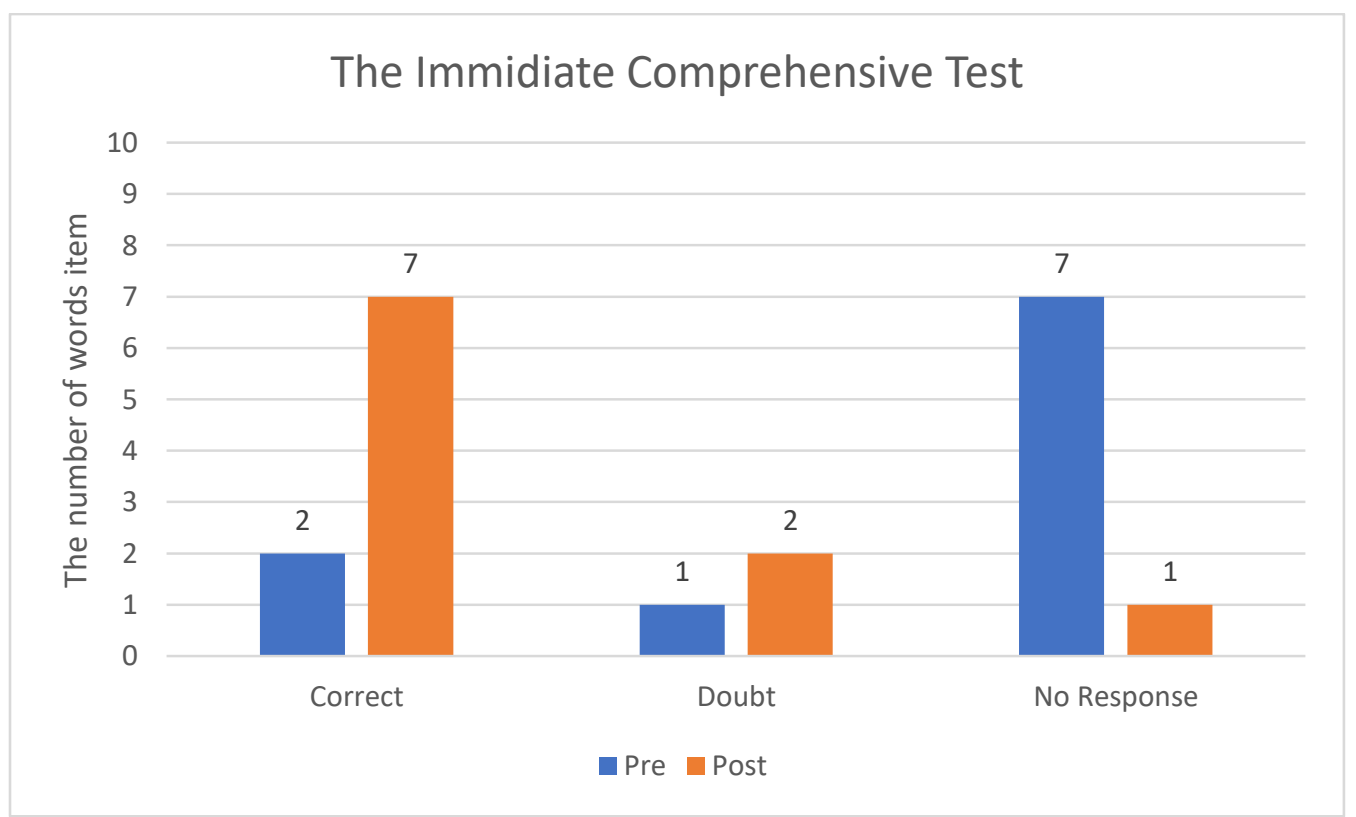

Figure 2. It presents the probability of Correct, Doubt, and No response over the period of the test trial carried on pre and post-intervention in the immediate comprehensive test.

Based on Figure 2, the subject just recalls 2\% for correct response of the items on the immediate comprehensive test while doubt response depicts $1 \%$. The highest percentage is no response items, demonstrated by $70 \%$ recall. In comparison with post-intervention, the subject experiences the increasing number of recalls. The subject is able to recall $70 \%$ correct. There are $2 \%$ in doubt response, and only $1 \%$ no response. It can be justified through this finding that the subject has successfully employed the KWM strategy in improving her FL vocabulary both acquisition and retention. This can be seen by identifying an increasing number of recalls on the correct response as the comparative ratio from $2 \%$ (pre-intervention) to $70 \%$ (postintervention) in the immediate comprehensive test. From this finding, the result indicated significant improvement in which the subject was able to memorize seven correct words pair in 
post-intervention in comparison with the pre-intervention session, merely two words pair or $70 \%$ and $20 \%$ respectively. Also, the subject's no response was lower in this section after intervention outlining $10 \%$ compared to before intervention, reaching $70 \%$.

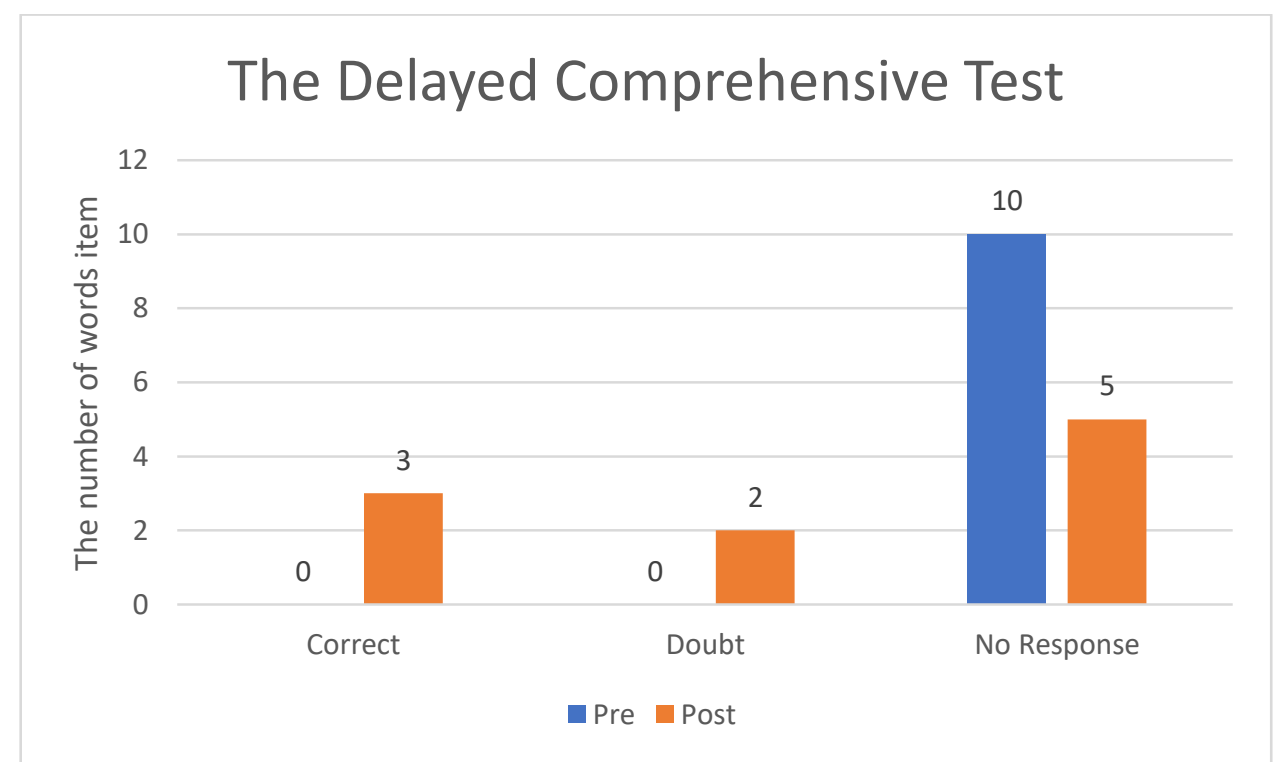

Figure 3. It presents the probability of Correct, Doubt, and No response over the period of the test trial carried on pre and post-intervention in the delayed comprehensive test.

In terms of the delayed comprehensive test covering 10-word pairs illustrated in Figure 3, the result shows that the KWM also successfully supports the subject in enhancing FL vocabulary acquisition and retention. Although the results do not significantly suggest a very satisfactory result, the data still depicts the higher percentage of the correct response after training the KWM strategy rather than her own strategy. Interestingly, based on observation, the subject could not recall any single word even the subject did not speak anything on the post delayed comprehensive test before training. In order words, the subject forgot all of them in her memory. While in the post comprehensive test conducted after training, the subject assertedly conveyed three correct words that the subject still remembered. Also, the subject attempted to recall two words, but the subject failed to recall correctly as illustrated in doubt responses. The striking items were demonstrated in no response items, in which both delayed comprehensive test before and after intervention outlines higher predominant items compared to correct and doubt responses. Zero percentage is gained in the delayed post-test before training. Moreover, the data shows a considerably decrease half of the previous one regarding the correct response illustrating the ratio of $70 \%$ to $30 \%$ examined in the immediate and the delayed comprehensive test after training.

In regard to interview section, the interview section has been done a couple of time to explore the subject's feelings and standpoints toward the KWM strategy. In more specifically, interview section has done in the first time before conducting intervention, during intervention and after intervention. After intervention, the experimenter attempted to observe by a direct question and answer such as one week after and followed two weeks after the last postintervention. Generally, the subject expressed that the KWM strategy was very helpful in order to support her memorization words. The subject felt more confident in remembering Indonesian 
words. Thereby, the repetition strategy is the most common techniques that the subject most often employs. However, after learning the KWM, including the main rules in the KWM implementation, the subject argued that this strategy is more helpful in her Indonesian study due to the associative learning, either through an acoustic link, similarity word pairs or imagery association. The detailed process is explored in the discussion below.

\section{DISCUSSION}

There are three main aims for this research that are illustrated in the hypothesis. Firstly, the KWM can support the first-year Indonesian studies student to enhance her Indonesian vocabulary acquisition and retention in comparison with her current study methods. Secondly, through the KWM, the learner can generate self-regulated learning in her foreign vocabulary learning. Additionally, cognition and metacognition actively become involved in the KWM implementation.

This research project appears to be the first attempt to investigate the process through which an Australian undergraduate student studies Indonesian FL learning. Overall, the results reveal that the KWM significantly facilitates the subject's ability in improving vocabulary acquisition and retention. This was apparent in the immediate and delayed comprehensive tests, covering the comparable 10-word pairs each trial or 20-words pair in total, in the two trials that were compared to the subject's own learning strategies. Hence, it can be justifiably concluded that the KWM strategy is more successful when memorizing foreign vocabulary and this supports other research findings described above.

The successful process of the KWM implementation is due to the strategy that stimulates learners to associate the acoustic and imagery links between the new foreign words and the native spoken words. Also, the strategy encompasses the involvement of cognition and metacognition processes. Learners need to find suitable spoken native words and then pair them with the new foreign words. This process produces a cognitive effort when the learner does not find any word in her memory to be retrieved through LTM. Therefore, prior knowledge of the subject plays an important role in identifying each word-pair. This is also helpful in terms of generating an imagery link regarding uncorrelated word-pairs and in producing associative meanings of the words. This kind of activity assists encourages the learner to think deeper. Craik and Lockhart (1972) have explained that thinking more deeply, rather than from a shallow perspective, can establish a good understanding of word meanings, especially in vocabulary acquisition for a foreign language. The learner is potentially able to perform better in terms of vocabulary recall due to the deeper cognitive effort. Nevertheless, a study conducted by McLoone et al. (1986) found that if the learners do not have sufficient prior knowledge, they are more likely to focus on inventing keywords rather than studying the language itself. This enables the subject to get word-lost in what they have memorized. Besides, insufficient prior knowledge causes the subjects to be unsuccessful in terms of the KWM implementation, especially when the KWM requires the learners to link the word-pair to image-able words (Atkinson \& Raugh, 1975; Raugh et al., 1977).

Based on observations during this project, when the experimenter gave 10-word pair list in the pre-intervention and then conducted the immediate test, the first word the subject said was "kupon" as the new foreign word and the keyword was "coupon". Both words are identical and have almost the same meaning as English translation. At the same time, "kupon" was placed in the middle list of 10-word pair displayed in the PowerPoint slide. The subject decided 
to choose "kupon" as the first selected word instead of other remaining words. This indicated that the subject applied the judgment of learning in determining the first word. This is closely related to strategy knowledge. Wyra and Lawson (2018) explained that strategy knowledge related to students' knowledge was gained from a variety of sources such as friends, books, magazines, entertainments and so on. The subject, in turn, knew "coupon" in her spoken language through her experience as a native speaker. Although the subject never learns and knows the KWM strategy, the subject unconsciously employed the KWM strategy through strategy knowledge as illustrating the first word "kupon" in the observation above. The subject's strategy knowledge is able to address problem solving by looking at the close relationship between word pairs. Desrochers (1982) also argued that close similarity in the words pair assists the learner in establishing associative learning. The finding was also supported by Morra and Camba (2009) and Baddeley et al. (1998) who emphasised the role of the phonological loop in working memory. They said that phonological sensitivity is a significant predictor when the word pair has a familiarity with the native language in associative learning, although Baddeley et al. (1998) further suggested that the phonological loop functioned as an aid for processing of the new word.

At the beginning of information processing, the subject's cognitive processes collaborate continually in the working memory and long-term memory. As an illustration, the subject completed coding "kupon" in the working memory and then transferred the information in the LTM. LTM, according to Flower and Hayes (1981), is demonstrated as a storehouse of knowledge employed in constructing current information collaboratively with the working memory. The "coupon" itself is retrieved through an encoding process in the episodic structure. The schemata in this stage of retrieval have a role to determine how new information is processed (Sweller, 1994). The subject's prior knowledge of "coupon" was very helpful in generating an associated word-pair. Prior knowledge is illustrated as being the data storage stored in memory (Bruning et al., 1999; Rumelhart, 2017). The subject is able to encode, represent, and retrieve information (Bruning et al., 2010). In other words, the subject implemented metacognition awareness and self-regulated learning by utilising a host of cognitive skills.

However, the subject was just able to spontaneously say "kupon" but then the subject was not able to properly utilize her self-regulated learning. This can be seen from the result of pre intervention where the subject was just able to recall two correct words in the immediate comprehensive test (Figure 2) and was not able to recall any single word in the delayed comprehensive test (Figure 3). Self-regulated learning, also called "self-direct process", includes metacognitively, motivationally and behaviorally being able to transform mental abilities into academic skills (Zimmerman, 2000). This process requires the subject to control and manage her learning in terms of thoughts, feelings and actions towards targeted outcomes (Bruning et al., 2010; Schunk \& Zimmerman, 1994). Based on the interview section after the completion of the delayed comprehensive test, the subject expressed the view that "I do not remember anything, all gone." Through this finding, it can be concluded that the subject certainly had difficulty in memorizing foreign words and the subject is not able to employ self-regulated learning in a more appropriate way.

The difficulty in memorizing paired-associate learning can be dealt with in memory strategy. However, this memory strategy can result in the emergence of a new issue, being the difficulty when the number of items on the list is too many. This was observed by Sweller 
(1994) who argued that the number of items on the list influences the extent of difficulty. More specifically, this is the case when the learner has not yet found the best strategy that can be employed. Repetition is the most common strategy employed by students when they attempt to remember words (See Benjamin, 2001; Davis \& Kim, 2001; Ellis \& Beaton, 1993; Lawson \& Hogben, 1998). The project's subject had employed repetition strategy in remembering words. This fact is based on her argument that the observer heard in the interview session and through observation of her while memorizing the word pair. Another issue that may arise is the limited time for memorizing words. Researchers, therefore, have attempted to identify the most efficient strategy for overcoming issues of time. Cognitive load, in turn, is more likely to occur due to greater demands in the higher processing information in working memory (See Sweller, 1994). In particular, the human brain has a limited capacity in cognitive resources (Sweller, 2011). Working memory, according to Bruning et al. (2010), is very limited in duration and capacity. In order to enhance working memory capacity and duration, Dempster (1985) argued that proper strategy use is more likely to supplement functional working memory. Proper study skills can be gained from other sources such as books, friends and teachers. As explained by Wyra and Lawson (2018) that students' strategy knowledge also can help the learners in addressing the tasks. Thereby, the KWM strategy has proven the effectiveness strategy in memorizing FL learning, although the KMW strategy has experimented over a very brief time for each item for the subjects (See Atkinson \& Raugh, 1974; Ernest \& Paivio, 1971; Levin, Pressley, McCormick, Miller, \& Shriberg, 1979). Given the KWM's rules involved the uses of imagery and acoustic link, the KWM strategy is more likely to optimize the learner's capacity itself.

If it refers to an explanation by Sweller (1994), the paired associate task ought to include the level of interactivity that can be meaningful. This eventually reduces the high demand for cognitive load in information processing. The higher level of imageable word pair influences the extent the learner is able to associate the word pair. Concrete nouns are likely to be more imageable words compared to abstract words (Atkinson, 1975; Atkinson \& Raugh, 1974, 1975; Ernest \& Paivio, 1971; Paivio \& Desrochers, 1981) and this is in accordance with dual coding theory developed by Paivio (1971) regarding the imaginal processing.

Furthermore, referring to the result findings, after the intervention session, especially in the delayed comprehensive test (Figure 3), the subject was just able to memorize three correct words. This number was far different compared to the immediate comprehensive test in which the subject was able to memorize seven correct words pair (Figure 2), outlining 30\% and $70 \%$ respectively. Also, the subject's no response was much higher in this section, demonstrating a $50 \%$ rate compared to the immediate comprehensive test of 10\% (Figure 2). From this fact, it can be concluded that the intervention employing the KWM strategy clearly works well when the subject undergoes the immediate comprehensive test, but it is not really useful in the delayed comprehensive test. This finding supports the conclusion of many experts that found that the KWM strategy is more helpful in producing recall results, if it is done in the immediate test rather than in the delayed test (Atkinson, 1975; Campos, Camino, \& Pérez-Fabello, 2011; Lawson \& Hogben, 1998; Raugh et al., 1977).

Before the intervention session conducting the immediate comprehensive test, the subject achieved only two correct recalls and the rest dominated by no response, reaching $70 \%$. Surprisingly, in the delayed comprehensive test (Figure 3), the subject could not recall any single word. Furthermore, doubt response is still considered as an important point in this 
intervention since doubt, in this process, indicates uncertainty to respond to the word pair. This means, the subject still remembers the words that has been memorized, even though the memory might still be disordered. This is a far better result than remembering nothing about a single word in her mind. In more detail, the correct responses between after and before intervention are illustrated as $70 \%$ and $20 \%$ in the immediate comprehensive test respectively and $30 \%$ and $0 \%$ in the delayed comprehensive test. Also, above $70 \%$ no recalls have been elicited by the subject in both the immediate and delayed comprehensive tests before intervention. Through this comparative finding, it is undeniable that the KWM strategy definitely produces a better method rather than her personal strategy.

Even so, in the process of intervention, the subject has raised some questions when seeking to clarify her understanding. These included asking, "Do I need to memorize the English translation?" and "Do I need to mention the keyword while memorizing the word pair?" The subject also employed self-assertiveness in order to determine whether her understanding is right or not. This included the statement like "I do need to link the new word and the keyword, look at the similarity of the sound, link to my previous knowledge to find the match-word etc." These processes, in turn, illustrate that the subject established metacognitive monitoring and self-regulated learning in achieving comprehensive understanding of the KWM strategy. Askell-Williams, Lawson, and Skrzypiec (2012) argue that "recheck" action be categorized as one of metacognitive strategies in terms of monitoring and control. If this refers to the self-regulated learning definition, self-regulated learning includes leaner's metacognitive strategies for planning, monitoring and modifying her cognition (Pintrich \& De Groot, 1990; Schunk \& Zimmerman, 1994). Bruning et al. (2010) explained self-regulated learning as the ability to control all aspects of one's learning. To examine her understanding in the final intervention session, the test facilitator raised the question to the subject, "Do you understand how to employ the KWM?" The subject then replied with the answer "Yes" and then explained the rules in the KWM implementation, such as the acoustic link and imagery link in word pair.

This is the initial stage to identify the degree to which the subject's knowledge of the KWM demonstrated a robust understanding. According to Pressley, Borkowski, and Schneider (2010), knowledge can determine each strategy use. They further explained that if the knowledge base is not well established then problem solvers are not be dealt with due to poor strategy information. It is considered important to have a thorough understanding of the KWM implementation, including how to use the method and when. Based on Pressley, Borkowski, and O'Sullivan (1984), as cited in (Pressley et al., 2010), in the experiment of adding specific strategy knowledge to the KWM strategy, as implemented for children in grades 5 and 6 . The results revealed that more detailed information can assist enhance the transfer of the keyword method to learning foreign words. This is closely related to the limited working memory in terms of capacity and duration which needs to be addressed by providing a detailed strategy aid. According to (Dempster, 1985), detailed strategy use can support working memory performance. Therefore, through this investigation of the result findings in the postintervention of both the immediate and delayed comprehensive tests, the subject showed robust understanding regarding the KWM use. This was demonstrated by her self-assertiveness in explaining the KWM strategy to the observer. This can be seen in the high recall outcome of $70 \%$ in the immediate comprehensive test, even though the subject did not really perform well in the delayed comprehensive test, reaching only 30\% recall and two doubts. 
More importantly, the subject has applied the KWM in learning Bahasa Indonesia as a foreign language. This is consistent with what the subject said to the experimenter during her interview session. The subject explained that the KWM strategy is very helpful in her study of Bahasa Indonesia. To illustrate this point, the subject explained that she was able to create her own examples when employing the KWM strategy. The subject mentioned that the word "kotor" as a new foreign word (English translation, "dirty"), is similar with the word "motor" or "motorcycle". For the first time, the observer sought to ask here again in order to clarify as well as to examine her understanding, "How could "motor" be similar with "kotor?" The subject then gave an illustration by quoting the sentence created in her imagination, "The motorcycle is dirty". Additionally, the subject repeated the word "kotor" and "motor" that sounded similar so as to try to convince the experimenter. The subject also added that in terms of learning Bahasa Indonesia, the subject consciously attempted to link each Indonesian word to English word. Because this process occurs continuously, the subject gave the example that it is like a spontaneous thought in her mind when she seeks to identify an appropriate native word while trying to memorize foreign words.

This finding above suggests the subject developed a personal motivational belief, similar to the concept of self-efficacy developed by Bandura (1977), in order to control her learning particularly when addressing the challenge of vocabulary memorization. Self-efficacy is defined as self-belief in performing any task better in order to achieve specific outcomes (Bandura, 1977; Bandura \& Schunk, 1981; Mouland, 1994). This conviction enables the subject to sustain the self-regulation of motivation in term of determining goals and grade accomplishments (Bruning et al., 2010). Through the KWM strategy, the subject determined the specific strategy knowledge that in turn applied in her foreign vocabulary learning. Furthermore, self-belief asserted by the subject in regard to the effectiveness of the KWM in foreign vocabulary memorization, as mentioned in her point of view, eventually encouraged the subject to continue using the same strategy when addressing foreign vocabulary issues. Given that not all strategic learnings will suite each student, the subject demonstrated that the KWM strategy is really was suitable to her. Tseng, Dörnyei, and Schmitt (2006) stated "a specific learning activity may be strategy for one and non-strategic for another" (Tseng et al., 2006, p. 81).

The conclusion in this intervention is that the KWM strategy supported a first-year Indonesian studies student in enhancing her foreign language vocabulary learning in studying Bahasa Indonesia at Flinders University. The fact underpinned the research findings around the world in terms of the effectiveness of the KWM strategy in improving FL learners, both in vocabulary acquisition and retention. Moreover, the success of the KMW strategy cannot be separated from the involvement of the subject in applying this method. In more specific terms, the subject followed the instruction of the KWM strategy that requires the subject to link the sound(s) or the similarity of the words between a foreign language and native language and forming the imagery acquisition towards unrelated word pairs.

Tseng et al. (2006) has argued that the successful learning process is initiated from the learner's involvement in strategic learning in which they believe that the choice of strategy will increase their learning effectiveness. Subsequently, this leads to motivational control, such as maintaining subject's confidence in order to apply to the KWM strategy. This also influences metacognitive awareness in term of controlling a host of cognitive skills. Through the resulting findings, interview and observation, the subject is eventually shown to be able to generate self- 
regulated learning in her study of Bahasa Indonesia. The subject is also capable of implementing the KWM strategy to apply in her own learning context. In other words, the subject has the ability to monitor, assess, evaluate, and regulate her own learning and this is what support to self-regulated learning. In reference to the explanation of Zimmerman (2000), self-regulated learning includes metacognitive awareness, strategy use, and motivational control. Therefore, the project facilitator argues that those categories are inherent in the subject's own choice of employing the KWM strategy in order to improve her FL Indonesian vocabulary learning during her studies.

\section{REFERENCES}

Adams, M. J. (1994). Beginning to read: Thinking and learning about print: MIT press.

Anderson, J. R. (2005). Cognitive psychology and its implications: Macmillan.

Askell-Williams, H., Lawson, M. J., \& Skrzypiec, G. (2012). Scaffolding cognitive and metacognitive strategy instruction in regular class lessons. Instructional Science, 40(2), 413-443.

Atkinson, R. C. (1975). Mnemotechnics in second-language learning. American psychologist, 30(8), 821.

Atkinson, R. C., \& Raugh, M. R. (1974). An Application of the Mnemonic Keyword Method to the Acquisition of a Russian Vocabulary. Psychology and Education Series, Technical Report No. 237.

Atkinson, R. C., \& Raugh, M. R. (1975). An application of the mnemonic keyword method to the acquisition of a Russian vocabulary. Journal of experimental psychology: Human learning and memory, 1(2), 126.

Avila, E., \& Sadoski, M. (1996). Exploring new applications of the keyword method to acquire English vocabulary. Language learning, 46(3), 379-395.

Baddeley, A., Gathercole, S., \& Papagno, C. (1998). The phonological loop as a language learning device. Psychological review, 105(1), 158.

Baleghizadeh, S., \& Ashoori, A. (2010). The Effect of Keyword and Word List Methods on Immediate Vocabulary Retention of EFL Learners. Pakistan Journal of social sciences (PJSS), 30(2).

Bandura, A. (1977). Self-efficacy: toward a unifying theory of behavioral change. Psychological review, 84(2), 191.

Bandura, A., \& Schunk, D. H. (1981). Cultivating competence, self-efficacy, and intrinsic interest through proximal self-motivation. Journal of personality and social psychology, 41(3), 586.

Benjamin, A. S. (2001). On the dual effects of repetition on false recognition. Journal of Experimental Psychology: Learning, Memory, and Cognition, 27(4), 941.

Bruning, R. H., Schraw, G. J., \& Ronning, R. R. (1999). Cognitive psychology and instruction: ERIC.

Bruning, R. H., Schraw, G. J., \& Ronning, R. R. (2010). Cognitive psychology and instruction: PEARSON.

Campos, A., Camino, E., \& Pérez-Fabello, M. J. (2011). Using the keyword mnemonics method among adult learners. Educational Gerontology, 37(4), 327-335.

Campos, A., González, M. A., \& Amor, A. (2003). Limitations of the mnemonic-keyword method. The Journal of general psychology, 130(4), 399-413.

Condus, M. M., Marshall, K. J., \& Miller, S. R. (1986). Effects of the keyword mnemonic strategy on vocabulary acquisition and maintenance by learning disabled children. Journal of Learning Disabilities, 19(10), 609-613.

Craik, F. I., \& Lockhart, R. S. (1972). Levels of processing: A framework for memory research. Journal of verbal Learning and verbal Behavior, 11(6), 671-684. 
Davis, C., \& Kim, J. (2001). Repeating and remembering foreign language words: Implications for language teaching systems. Artificial Intelligence Review, 16(1), 37-47.

De Jong, N. H., Steinel, M. P., Florijn, A., Schoonen, R., \& Hulstijn, J. H. (2013). Linguistic skills and speaking fluency in a second language. Applied Psycholinguistics, 34(5), 893-916.

Dempster, F. N. (1985). Short-term memory development in childhood and adolescence Basic processes in memory development (pp. 209-248): Springer.

Desrochers, A. (1982). Imagery elaboration and the recall of French article-noun pairs. Canadian Journal of Psychology/Revue canadienne de psychologie, 36(4), 641.

Dolean, D. D. (2014). Using the keyword method in the classroom: Is the interacting imagery necessary? System, 45, 17-26.

Ellis, N., \& Beaton, A. (1993). Factors affecting the learning of foreign language vocabulary: Imagery keyword mediators and phonological short-term memory. The Quarterly Journal of Experimental Psychology, 46(3), 533-558.

Ernest, C. H., \& Paivio, A. (1971). Imagery and verbal associative latencies as a function of imagery ability. Canadian Journal of Psychology/Revue canadienne de psychologie, 25(1), 83.

Flavell, J. H. (1979). Metacognition and cognitive monitoring: A new area of cognitivedevelopmental inquiry. American psychologist, 34(10), 906.

Flower, L., \& Hayes, J. R. (1981). A cognitive process theory of writing. College composition and communication, 32(4), 365-387.

Forrest-Pressley, D.-L., \& Waller, T. G. (2013). Cognition, metacognition, and reading (Vol. 18): Springer Science \& Business Media.

Goldstein, E. B. (2014). Cognitive psychology: Connecting mind, research and everyday experience: Nelson Education.

Greaney, V. (1970). A comparison of individualized and basal reader approaches to reading instruction. The Irish Journal of Education/Iris Eireannach an Oideachais, 19-29.

Griffith, D. (1981). An evaluation of the key-word technique for the acquisition of Korean vocabulary by military personnel. Bulletin of the Psychonomic Society, 17(1), 12-14.

Gruneberg, M. M., \& Pascoe, K. (1996). The effectiveness of the keyword method for receptive and productive foreign vocabulary learning in the elderly. Contemporary Educational Psychology, 21(1), 102-109.

Harmon, J., Wood, K., \& Medina, A. (2009). Vocabulary learning in the content areas: Researchbased practices for middle and secondary school classrooms. Literacy instruction for adolescents: Research based practice, 344-367.

Hasselhorn, M., \& Labuhn, A. (2011). Metacognition and self-regulated learning.

Hemphill, L., \& Tivnan, T. (2008). The importance of early vocabulary for literacy achievement in high-poverty schools. Journal of Education for Students Placed at Risk, 13(4), 426-451.

Industries, M. F. (2017). Manfaat dan Khasiat Beras Putih untuk Kesihatan Anda!! Retrieved from https://www.meemuslim.com.my/2017/08/26/manfaat-dan-khasiat-beras-putihuntuk-kesihatan-anda/

Just, M. A., \& Carpenter, P. A. (1992). A capacity theory of comprehension: individual differences in working memory. Psychological review, 99(1), 122.

Kelley, J. G., Lesaux, N. K., Kieffer, M. J., \& Faller, S. E. (2010). Effective academic vocabulary instruction in the urban middle school. The Reading Teacher, 64(1), 5-14.

Koizumi, R., \& In'nami, Y. (2013). Vocabulary Knowledge and Speaking Proficiency among Second Language Learners from Novice to Intermediate Levels. Journal of Language Teaching \& Research, 4(5).

Krashen, S. (1989). We acquire vocabulary and spelling by reading: Additional evidence for the input hypothesis. The modern language journal, 73(4), 440-464. 
Lawson, M., \& Hogben, D. (1998). Learning and recall of foreign-language vocabulary: Effects of a keyword strategy for immediate and delayed recall. Learning and instruction, 8(2), 179-194.

Levin, J. R., Pressley, M., McCormick, C. B., Miller, G. E., \& Shriberg, L. K. (1979). Assessing the classroom potential of the keyword method. Journal of Educational Psychology, 71(5), 583.

Mastropieri, M. A., Scruggs, T. E., Levin, J. R., Gaffney, J., \& McLoone, B. (1985). Mnemonic vocabulary instruction for learning disabled students. Learning Disability Quarterly, 8(1), 57-63.

Mastropieri, M. A., Scruggs, T. E., \& Mushinski Fulk, B. J. (1990). Teaching abstract vocabulary with the keyword method: Effects on recall and comprehension. Journal of Learning Disabilities, 23(2), 92-96.

McLoone, B. B., Scruggs, T. E., Mastropieri, M. A., \& Zucker, S. F. (1986). Memory strategy instruction and training with learning disabled adolescents. Learning Disabilities Research.

Medium. (2018). Attention and Sensory Memory. Retrieved from https://medium.com/@JenBonhomme/attention-sensory-memory-2509047846e5

Miminku. (2016). Kucing Suka Sekali Menatap Keluar Lewat Jendela, Sebenarnya Mereka Ngapain Ya? Retrieved from http://www.petnyaku.com/facts/kucing-suka-sekalimenatap-keluar-lewat-jendela-sebenarnya-mereka-ngapain-ya/

Morra, S., \& Camba, R. (2009). Vocabulary learning in primary school children: Working memory and long-term memory components. Journal of Experimental Child Psychology, 104(2), 156-178.

Mouland, W. D. (1994). A study of the influence of instructional objectives on student self-efficacy. Memorial University of Newfoundland.

Olinghouse, N. G., \& Wilson, J. (2013). The relationship between vocabulary and writing quality in three genres. Reading and Writing, 26(1), 45-65.

Paivio, A. (1969). Mental imagery in associative learning and memory. Psychological review, $76(3), 241$.

Paivio, A. (1971). Imagery and verbal processes. New York, NY: Holt, Rinheart \& Winston. Paivio, A. 1986. Mental representation: A dual-coding approach: New York, NY: Oxford University Press.

Paivio, A. (1990). Mental representations: A dual coding approach: Oxford University Press.

Paivio, A., \& Desrochers, A. (1981). Mnemonic techniques in second-language learning. Journal of Educational Psychology, 73(6), 780.

Pearlman, I. (1990). Effectiveness of keyword versus direct instruction on vocabulary acquisition by primary-grade handicapped learners. Bulletin of the Psychonomic Society, 28(1), 14-16.

Pediwear. (2019). Saphir Large Shoe Brush. Retrieved from https://www.pediwear.co.uk/saphir-shoe-care/products/5646.php

Pintrich, P. R., \& De Groot, E. V. (1990). Motivational and self-regulated learning components of classroom academic performance. Journal of Educational Psychology, 82(1), 33.

Pressley, M. (1977). Children's use of the keyword method to learn simple Spanish vocabulary words. Journal of Educational Psychology, 69(5), 465.

Pressley, M., Borkowski, J. G., \& O'Sullivan, J. T. (1984). Memory strategy instruction is made of this: Metamemory and durable strategy use. Educational Psychologist, 19(2), 94-107.

Pressley, M., Borkowski, J. G., \& Schneider, W. (2010). Cognitive strategies: Good strategy users coordinate metacognition and knowledge. 
Pressley, M., \& Levin, J. R. (1978). Developmental constraints associated with children's use of the keyword method of foreign language vocabulary learning. Journal of Experimental Child Psychology, 26(2), 359-372.

Pressley, M., Levin, J. R., \& Delaney, H. D. (1982). The mnemonic keyword method. Review of Educational Research, 52(1), 61-91.

Pressley, M., Levin, J. R., \& Miller, G. E. (1981). The keyword method and children's learning of foreign vocabulary with abstract meanings. Canadian Journal of Psychology/Revue canadienne de psychologie, 35(3), 283.

Proust, J. (2010). Metacognition. Philosophy Compass, 5(11), 989-998.

Raugh, M. R., Schupbach, R. D., \& Atkinson, R. C. (1977). Teaching a large Russian language vocabulary by the mnemonic keyword method. Instructional science, 6(3), 199-221.

Roberts, J., \& Kelly, N. (1985). The keyword method: An alternative vocabulary strategy for developmental college readers. Literacy Research and Instruction, 24(3), 34-39.

Rodriguez, M., \& Sadowki, M. (2000). Effects of rote, context, keyword, and context/keyword methods on retention of vocabulary in EFL classrooms. Language learning, 50(2), 385412.

Rumelhart, D. E. (2017). Schemata: The building blocks of cognition Theoretical issues in reading comprehension (pp. 33-58): Routledge.

Sadoski, M. (2005). A dual coding view of vocabulary learning. Reading $\mathcal{E}$ Writing Quarterly, 21(3), 221-238.

Schunk, D. H., \& Ertmer, P. A. (2000). Self-regulation and academic learning: Self-efficacy enhancing interventions Handbook of self-regulation (pp. 631-649): Elsevier.

Schunk, D. H., \& Zimmerman, B. J. (1994). Self-regulation of learning and performance: Issues and educational applications: Lawrence Erlbaum Associates, Inc.

Shapiro, A. M., \& Waters, D. L. (2005). An investigation of the cognitive processes underlying the keyword method of foreign vocabulary learning. Language teaching research, 9(2), 129-146.

Siriganjanavong, V. (2013). The Mnemonic Keyword Method: Effects on the Vocabulary Acquisition and Retention. English Language Teaching, 6(10), 1-10.

Stæhr, L. S. (2009). Vocabulary knowledge and advanced listening comprehension in English as a foreign language. Studies in second language acquisition, 31(4), 577-607.

Staehr, L. S. (2008). Vocabulary size and the skills of listening, reading and writing. Language Learning Journal, 36(2), 139-152.

Sweller, J. (1994). Cognitive load theory, learning difficulty, and instructional design. Learning and instruction, 4(4), 295-312.

Sweller, J. (2011). Cognitive load theory Psychology of learning and motivation (Vol. 55, pp. 37-76): Elsevier.

Troutt-Ervin, E. D. (1990). Application of keyword mnemonics to learning terminology in the college classroom. The Journal of Experimental Education, 59(1), 31-41.

Tseng, W.-T., Dörnyei, Z., \& Schmitt, N. (2006). A new approach to assessing strategic learning: The case of self-regulation in vocabulary acquisition. Applied linguistics, 27(1), 78-102.

Tulving, E. (1972). Episodic and semantic memory. Organization of memory, 1, 381-403.

Van Hell, J. G., \& Mahn, A. C. (1997). Keyword mnemonics versus rote rehearsal: Learning concrete and abstract foreign words by experienced and inexperienced learners. Language learning, 47(3), 507-546.

Walker, N., Jones, J. P., \& Mar, H. H. (1983). Encoding processes and the recall of text. Memory $\mathcal{E}$ Cognition, 11(3), 275-282. doi:10.3758/bf03196974

Wang, A. Y., \& Thomas, M. H. (1992). The effect of imagery-based mnemonics on the long-term retention of Chinese characters. Language learning, 42(3), 359-376. 
Wells, G. (1985). Preschool literacy-related activities and success in school. Literacy, language, and learning, 229-255.

Willerman, B., \& Melvin, B. (1979). Reservations about the keyword mnemonic. Canadian Modern Language Review, 35(3), 443-453.

Wyra, M., \& Lawson, M. J. (2018). Foreign language vocabulary learning using the keyword method: strategy and meta-strategy knowledge. The Language Learning Journal, 46(5), 605-621.

Wyra, M., Lawson, M. J., \& Hungi, N. (2007). The Mnemonic Keyword Method: The Effects of Bidirectional Retrieval Training and of Ability to Image on Foreign Language Vocabulary Recall. Learning and Instruction, 17(3), 360-371. doi:10.1016/j.learninstruc.2007.02.008

Zimmerman, B. J. (1990). Self-regulated learning and academic achievement: An overview. Educational Psychologist, 25(1), 3-17.

Zimmerman, B. J. (2000). Attaining self-regulation: A social cognitive perspective Handbook of self-regulation (pp. 13-39): Elsevier.

Zimmerman, B. J., Bandura, A., \& Martinez-Pons, M. (1992). Self-motivation for academic attainment: The role of self-efficacy beliefs and personal goal setting. American educational research journal, 29(3), 663-676. 